\title{
THE INFLUENCE OF NON-ESTERIFICATION BIODIESEL IN AN INDIRECT INJECTION DIESEL ENGINE
}

\author{
SEUNG-HUN CHOI \\ The Research Center of Industrial Technology, Chonbuk National University, \\ Deokjin-dong, Deokjin-gu, Jeonju, Jeonbuk, 561-756, Korea \\ medr@jbnu.ac.kr \\ YOUNG-TAIG OH* \\ Department of Mechanical Engineering, The Research Center of Industrial \\ Technology, Chonbuk National University, Deokjin-dong, Deokjin-gu, Jeonju, \\ Jeonbuk, 561-756, Korea \\ ohyt@jbnu.ac.kr
}

\begin{abstract}
Biodiesel as alternative energy source of the traditional petroleum fuels has increased interest, because environmental pollution based exhaust emissions from vehicle became serious. The advantage of biodiesel produced from esterification of vegetable and animal oils can be used without the modification of existing diesel engine, but glycerin is generated by production process. In this study, the usability of non-esterification biodiesel as an alternative fuel was investigated in an indirect injection diesel engine. The non-esterification biodiesel has not generated glycerin in esterification process and reduced the 20 percent of cost because it has not used methanol in the production process. Experiments were conducted by using the 5,10 and 20 percentage of biodiesel and 4 and 8 percentage of biodiesel with 1 and 2 percentage of WDP in baseline diesel fuel. The smoke emission of biodiesel was reduced in comparison with diesel fuel, but power, torque and brake specific energy consumption was similar to diesel fuel.
\end{abstract}

Keywords: Indirect injection diesel engine, non-esterification biodiesel, WDP (Water Dipole Power), BSEC (Brake Specific Energy Consumption), smoke.

\section{Introduction}

Serious global environmental problems and the depletion of limited resource of fossil fuels currently requires extensively being for the vast majority of energy replacement fossil fuels to environmentally friendly renewable energy. ${ }^{1,2}$ Arising from vehicle exhaust emissions especially the impact of environmental pollution becomes a seriously according to the conventional petroleum-based biodiesel fuels have been increased to interest significantly as alternative energy sources. ${ }^{3,4}$ Already in Europe since the mid of 1990s using biodiesel brand with diesel mixed and the current status prevalence rate was less than $1.0 \%$ compared to diesel but it's pushing to expand $12 \%$ in 2010 .

\footnotetext{
*Corresponding author: ohyt@jbnu.kr
} 
In Korea, the Renewable Energy Program executed by government announced in 2004 and plans to expand biodiesel utilization until 3\% in 2011.

The Ministry of Industry and Energy supplying a biodiesel for distribution pilot area by $20 \%$ blended biodiesel then generally has a policy to expand in all area spread of biodiesel usage from November 2002. Generally biodiesel produced by vegetable, animal oil by esterification process and biodiesel fuel has some good advantages when used in the conventional diesel engine without any kind of editing process of engine design parts. However, there are disadvantages such as low oxidative stability, cold flow temperature and easily deterioration of biodiesel than compared to diesel. ${ }^{5}$ To solve these problems Ref. 6 have reported that the blending method of ethanol with biodiesel in order to improve low temperature fluidity. Note that the additional costs will occur during biodiesel production by esterification method approaches to the treatment of glycerol obtaining process.

In this study, the usability of non-esterification biodiesel as an alternative fuel was investigated in an indirect injection diesel engine through a new process which is not being used spatial. Non-esterification process of biodiesel have not been generated glycerin in conventional erterification process and accounting for $20 \%$ of production cost reduction savings can be acquired through a price-competitive advantages without use of methanol in the production. Accordingly, in this study non-esterified biodiesel from fuel additives (WDP; water dipole power) was applied to a mixture of fuel for indirect injection diesel engine. And this blended fuel effects on diesel engine were analyzed through engine performance and exhaust gas emission characteristics compared to commercial diesel fuel.

\section{Experimental apparatus and methods}

The engine used in this experiment was 4 cylinder, water-cooled, 4 strokes, indirect injection diesel engine. And the engine load and rotational speed can be adjusted arbitrarily by using engine dynamometer. The specification of the engine used in the experiment is shown in Table 1 and the fuel characteristics listed in Table 2. Biodiesel fuel contains approximately $11.6 \%$ oxygen concentration. In addition, this biodiesel tested as an additive mixed with WDP significantly improves low temperature contains approximately $26.62 \%$ oxygen concentration.

Table 1. Specification of test engine.

\begin{tabular}{lc}
\hline \multicolumn{1}{c}{ Item } & Specification \\
\hline Number of cylinder & 4 \\
Bore $\times$ Stroke & $91.1 \times 95(\mathrm{~mm})$ \\
Displacement & $2476(\mathrm{cc})$ \\
Compression ratio & 21 \\
Combustion chamber & Pre-chamber \\
Coolant temperature & $80 \pm 2^{\circ} \mathrm{C}$ \\
Injection type & Indirect injection \\
\hline
\end{tabular}

Table 2. Properties of test fuels.

\begin{tabular}{lccc}
\hline & $\begin{array}{c}\text { Diesel } \\
\text { Fuel }\end{array}$ & BD & WDP \\
\hline $\begin{array}{l}\text { Specific gravity } \\
\left(15^{\circ} \mathrm{C}\right)\end{array}$ & 0.83 & 0.90 & 0.79 \\
$\begin{array}{l}\text { Calorific } \\
\text { value( } \mathrm{MJ} / \mathrm{kg})\end{array}$ & 43.96 & 34.70 & 16.60 \\
$\begin{array}{l}\text { Carbon }(\mathrm{wt} \%) \\
\text { Hydrogen }(\mathrm{wt} \%)\end{array}$ & 86.76 & 76.49 & 59.90 \\
Oxygen $(\mathrm{wt} \%)$ & 13.05 & 12.11 & 13.31 \\
\hline
\end{tabular}




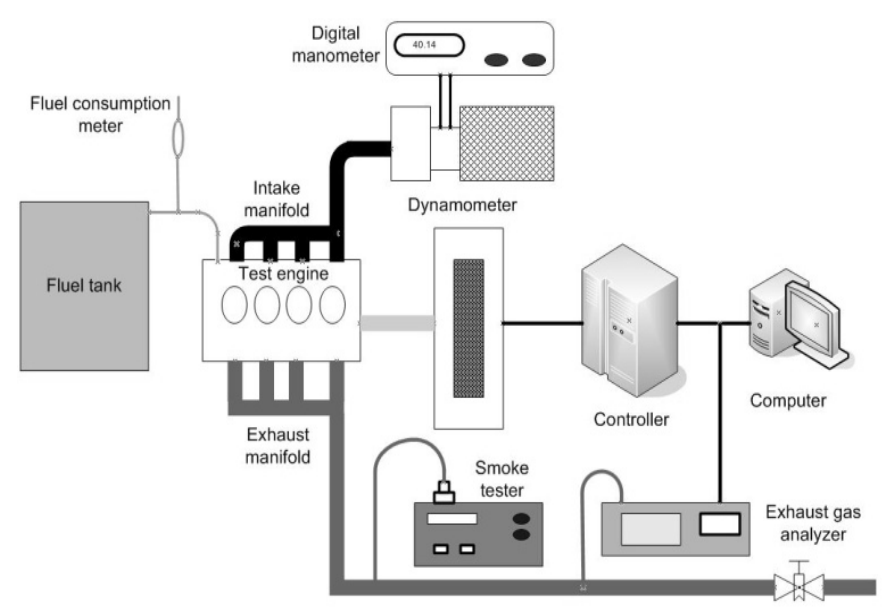

Fig. 1. Schematic diagram of experimental apparatus.

In addition, this biodiesel tested as an additive mixed with WDP significantly improves low temperature flexibility. In this experiment was used the basis of commercial diesel blended with $5 \%, 10$ and $20 \%$ of the volume mixing ratio of biodiesel, and also $4 \%, 8 \%$ biodiesel fuel with WDP $1 \%, 2 \%$, respectively mixture compared with only diesel fuel. Smoke concentration measurement performed by the smoke measuring device (Hesbon; HBN-1500) in the downstream of $300 \mathrm{~mm}$ from the engine after inhalation certain amount of exhaust gas. The concentration of smoke adsorbed on filter paper was taken under the same measuring conditions then average of every three values was used for the analysis. Measuring $\mathrm{CO}_{2}, \mathrm{O}_{2}$ and $\mathrm{NOx}$ approximately $400 \mathrm{~mm}$ downstream from the exhaust manifold made by gas analyzer (Greenline MK2; Italy) after a certain amount of exhaust gas inhalation. In addition, energy consumption per unit time (MJ / kW.h) was calculated by measuring the fuel consumption of the engine.

\section{Results and discussion}

Fig. 2 shows the engine load and torque change applied to various mixing ratio of WDP blended biodiesel fuel for indirect injection diesel engine compared to diesel fuel only. As shown in this Figure, biodiesel blending percent increased as the rate of torque decreased. Torque degradation was occurred only $1 \%$ when use $5 \%$ biodiesel mixture at $2500 \mathrm{rpm}$ rotational speed and engine full load area. But biodiesel mixing rates were $10 \%$, $20 \%$ the torque degradation was found about $2.8 \%$ and $4.2 \%$, respectively. This means that the biodiesel calorific value was about $21 \%$ lower if compared with diesel and it can be considered biodiesel fuel influenced to improve combustion efficiency due to high oxygenated ingredients. In addition, there is no significant difference between two kinds of fuels as WDP blended biodiesel and diesel fuel only. In the case of making experiment of biodiesel $4 \%$ with 1\% WDP and biodiesel $8 \%$ with WDP applied to $2 \%$ compared biodiesel $5,10 \%$ blending rates the torque degradation generated by less than $0.2 \%$ it is validated that little difference considerably concentration of blending percent from WDP. 
Fig. 3 shows the parameters under the same conditions as shown in Fig. 2 and represented the engine load with change of braking energy consumption (BSEC; brake specific energy consumption). As shown in this Figure, there is almost no difference compared between the biodiesel and diesel fuel BSEC percentage at various rotation speed of engine. Engine combustion appeared as an effectively improvement due to oxygen containing in the biodiesel fuel itself.

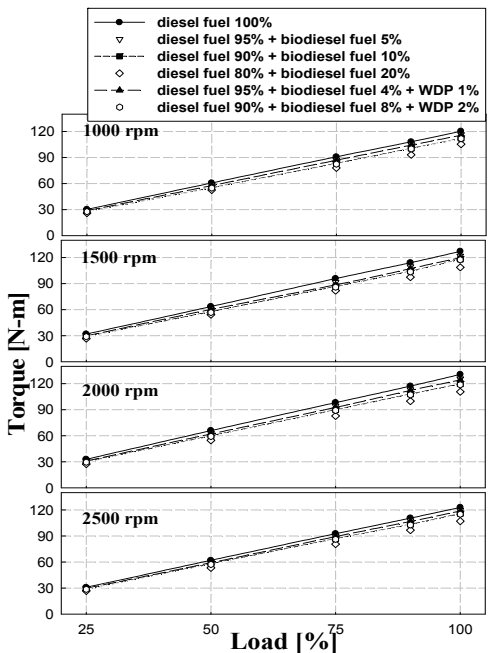

Fig. 2. Torque versus different biodiesel contents under various engine speeds.

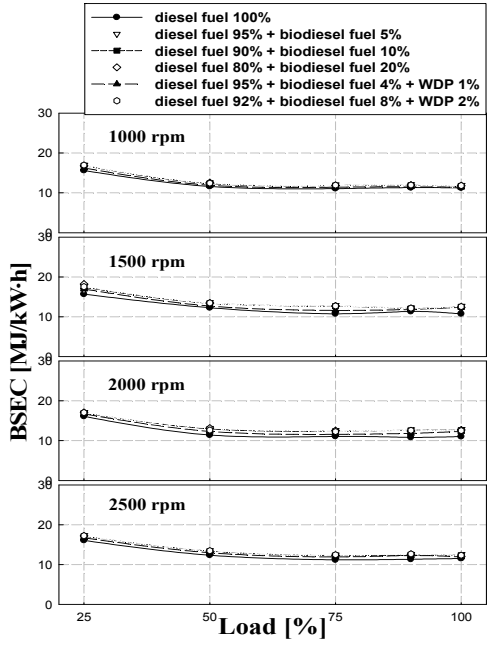

Fig. 3. BSEC versus different biodiesel contents under various engine speeds.

In other words, increasing the concentration of oxygen in the combustion chamber the reaction rate is increased. Especially, combustion thought to be stabilized faulty in a wider range of area of heavy-duty due to increases combustion reaction rate.

Fig. 4 represents the engine load applied according to the institution of smoke emission characteristics of the WDP mixed biodiesel fuel percentage and commercial diesel fuel at various rotation speeds respectively. Especially, as shown in Fig. 4 biodiesel blended fuel can significantly reduces engine smoke emissions even more increasing the engine load and rotation speed. The biodiesel blend rates were increasing by $5 \%, 10 \%$ and $20 \%$ then smoke emissions decreased by $14.3 \%, 26.9 \%$ and $46.5 \%$ respectively when compared with diesel fuel only at rotation speed of $2500 \mathrm{rpm}$ with full load area. Typically, from the theory of diesel engine commercial fuel combustion has incomplete situation during the more concentration due to the lack of air. So in this case high smoke percentage occurs in the diesel fuel but when using more oxygen containing biodiesel blended fuel here contributed to improve combustion procedure and there have been reduced smoke rapidly.

Fig. 5 shows the NOx emissions characteristics result which are the same conditions as illustrated in Fig. 4. As shown in this Figure, the heavy-duty areas progressed NOx emissions tends to increase with biodiesel fuel mixture significantly and also when 
increasing biodiesel fuel blending percent amount then NOx emissions are also found to be increased. Changing biodiesel fuel blending ratio from $5 \%, 10 \%$ to $20 \%$ then $\mathrm{NOx}$ emissions increased rate was $7.4 \%, 9.2 \%$ and $12.4 \%$, respectively when compared with

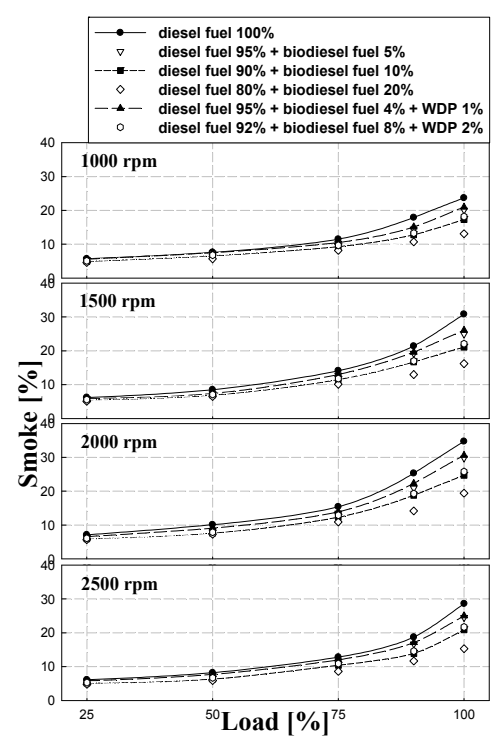

Fig. 4. Smoke versus different biodiesel contents under various engine speeds.

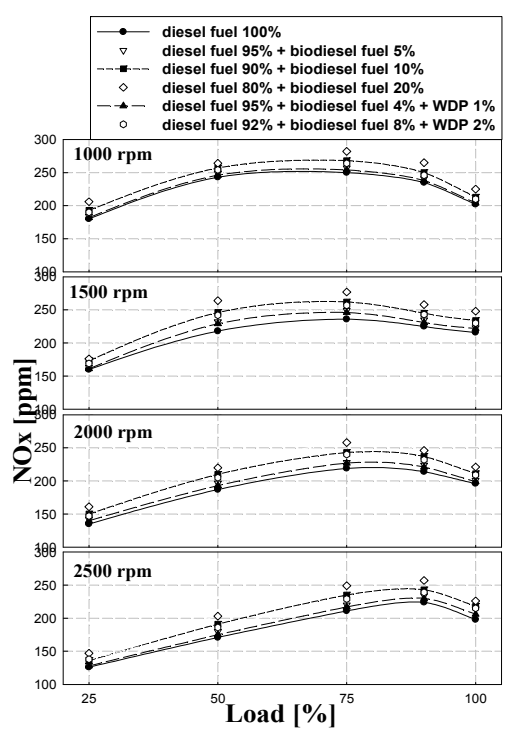

Fig. 5. NOx versus different biodiesel contents under various engine speeds

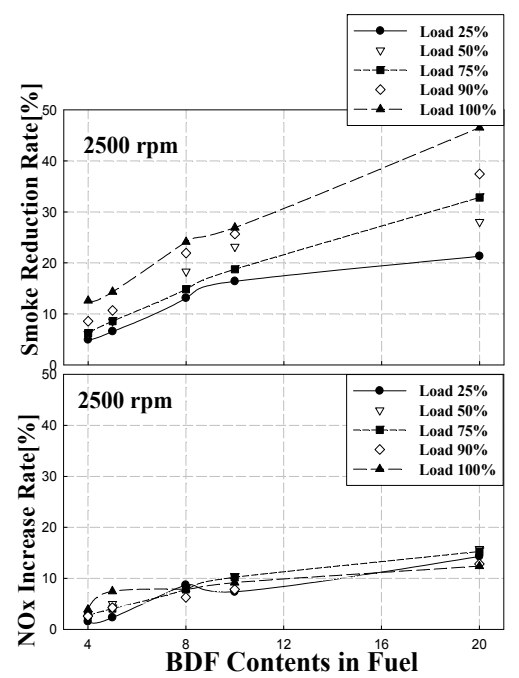

Fig. 6. Smoke and NOx variation rate versus various engine loads at $2500 \mathrm{rpm}$. 
diesel used only at $2500 \mathrm{rpm}$ rotation speed. NOx emissions may be increased due to the high oxygen contained biodiesel fuel combustion temperature activates to rise in the combustion chamber during combustion caused by the high thermal efficiency. ${ }^{8}$

Fig. 6 shows the smoke and NOx rates according to various biodiesel blend percent at $2000 \mathrm{rpm}$ rotation speed of engine. It can be seen that NOx increase rate growth was lower than the smoke reduction rate amount. The rate of smoke reduction looks like in this graph whereas engine load increased case then smoke reduction rate increasing caused by lot of fuel supply in heavy-duty progressed condition into the quickly contribution of more oxygen contained in the fuel. ${ }^{9}$

\section{Conclusion}

This research work performed the experiments of indirect injection diesel engine performance and exhaust emission characteristics by applying 5-20\% biodiesel blended commercial diesel fuel with WDP additive. And biodiesel experiments results have compared to pure diesel characteristics then following conclusions were obtained from this research.

(a) Smoke reduction was found up to $46 \%$ if biodiesel fuel mixing ratio was $20 \%$ at 2500 rpm rotational speed of engine with full load area.

(b) NOx was observed to increase by applying the biodiesel mixture percent to commercial diesel due to high thermal efficiency and NOx increment rate was over than smoke reduction rate growth exceeds.

\section{References}

1. S. H. Choi and Y. T. Oh, J. of KSPSE. 9, 15 (2005).

2. S. H. Choi and Y. T. Oh, J. of KSPSE. 10, 2 (2006).

3. S. H. Choi and Y. T. Oh, Transactions of KSAE. 15, 3 (2007).

4. S. H. Choi and Y. T. Oh, Transactions of KSAE. 16, 4 (2008).

5. S. H. Park and H. J. Kim, J. of Ilass-Korea. 13, 4 (2008).

6. T. Shudo et al., SAE technical paper. 01, 3707 (2005).

7. Y. T. Oh and S. H. Choi, Transaction of IJAT. 6, 3 (2005).

8. R. Rota and E. F. Zanoelo, Fuel. 82,765 (2003).

9. C. Y. Choi and R. D. Reitz, Fuel. 78,1303 (1999). 